\title{
Malaysia's Energy-Growth Nexus and Environmental Kuznets Curve Hypothesis: Empirical Analysis Using the VECM and ARDL Cointegration Techniques
}

\author{
Takashi Fukuda \\ Independent researcher \\ 1-5-81-401, Toroku, Chuouku, Kumamoto, 8620970, Japan \\ Tel: +81-90-3734-8156Ｅ-mail: takashi@fukuda-kieg.com
}

Received: October 24, 2021 Accepted: November 8, 2021 Published: November 15, 2021

doi: 10.52941/jad.v8i1.22 URL: https://doi.org/10.52941/jad.v8i1.22 


\section{Abstract}

This paper investigated Malaysia's energy-growth nexus and environmental Kuznets curve (EKC) hypothesis over the period 1971-2014 by taking the globalization variables of trade openness and foreign direct investment (FDI) and the structural break dummy of the Asian financial crisis of 1997 into estimation. To give interference, the Granger causality tests were implemented in the framework of two cointegration techniques: vector error correction model (VECM) and autoregressive distributed lag (ARDL). As per Malaysia's energy-growth nexus, referring to different results of the two approaches, we concluded that the presence of the energy-growth nexus was statistically confirmed, but it has not been fully established yet in the country. On the other hand, both the VECM and ARDL results provided the same conclusion for Malaysia's EKC hypothesis, that is, in the initial stage, as the higher economic growth, the less $\mathrm{CO}_{2}$ emissions, but after a threshold, the higher economic growth, the more $\mathrm{CO}_{2}$ emissions.

Keywords: Energy-growth nexus; Environmental Kuznets curve (EKC); Globalization; Structural break; VECM; ARDL; Granger causality; Malaysia

\section{Introduction}

Energy is very important for economic development which has been typically enabled by fossil fuel-based energy consumption. In the literature, the energy-growth nexus-the relationship between energy consumption and economic growth-is a field attracting major research attention. Studying the energy-growth nexus can provide the significant information to policy-makers who consider energy conservation measures (Menegaki, 2019) because the implementation of energy conservation policies may severely affect economic performance and retard economic development (Ang, 2008). Since the late 1970s, many empirical studies on the energy-growth nexus have been conducted, but the debate on the energy-growth nexus is so far inconclusive.

Meanwhile, as energy consumption is very relevant to rapid exhaustion of natural resources and environmental pollution, the pattern of world energy consumption is becoming unsustainable. In particular, the demand for energy in emerging countries has risen due to their increasing income. In order to fulfil the growing demand for energy, emerging countries need more production, which leads to more energy consumption. As a result, global warming has been one of the biggest challenges to human being, and it is evident that the main source of this warming is $\mathrm{CO}_{2}$ emissions. As inferred from the fact that the United Nation's sustainable development goals (SDGs) and the Paris Agreement have been the hottest topics, the relationship between environmental sustainability and economic growth is an important issue in terms of policy and academia. In this regards, the environmental Kuznets curve (EKC) hypothesis, which postulates an inverted-U-shaped relationship between environmental pollutants and economic growth, has been hotly discussed in the literature (see Grossman and Krueger, 1991).

The energy-growth nexus and EKC do not necessarily depend on economic growth, energy and $\mathrm{CO}_{2}$ emissions only; other variables also must be very influential for them. For example, as the 
effects of international trade (exports + imports) and foreign direct investment (FDI) on economic growth have been emphasized, their environmental impacts have been also recognized. It is pointed out that cross-border movement of resources-brought about by the increasing extent of globalization-must exhibit a significant impact on the economic growth as well as on $\mathrm{CO}_{2}$ emissions pattern worldwide via the energy consumption channel (Shahbaz et al., 2021). Hence we assume that there is a substantial relationship between globalization and environmental sustainability; policymakers cannot target the sustainable growth in future if they are not able to identify the linkages between the key economic variables (Arif et al., 2020).

The objective of the present paper is to empirically investigate Malaysia's energy-growth nexus and EKC hypothesis over the period 1971-2014 taking the globalization variables of trade openness and foreign direct investment (hereafter FDI), together with a structural break dummy of the Asian financial crisis of 1997 into estimation. Malaysia is an interesting case for this research topic as it is known as a fast growing country but also is an energy-dependent country consuming a large amount of natural resources and experiencing a high pace of globalization.

The present paper's contribution to the literature is elucidated as follows. There are several empirical studies examining Malaysia's energy-growth nexus and EKC (e.g., Ang, 2008; Lean and Smyth, 2010; Islam et al., 2013; Bekhet et al., 2013; Etokakpan et al., 2020), but we do not see an in-depth analysis which extensively addresses the two topics simultaneously employing latest data series. To provide clear policy implications for Malaysia's sustainable development, we attempt to fulfil this vacant area by using two cointegration techniques of autoregressive distributed lag (ARDL) and vector error correction model (VECM).

In the rest of the paper, the relevant literature is reviewed in Section 2. The basic models and data are given in Section 3. Methodology is explained in Section 4. Empirical findings are presented and discussed in Section 5. Finally, we present conclusions and policy implications in Section 6.

\section{Literature Review}

\subsection{Energy-Growth Nexus}

As initiated by the seminal work of Kraft and Kraft (1978) who investigated the United States' case, the relationship between energy consumption and economic growth has been extensively studied in the literature. As the "energy-growth nexus" economics is a field that attracts major research attention, we can see several empirical studies on the energy-growth nexus, which focus on different countries, time periods and proxy variables, using different econometric methodologies. However, the energy-growth nexus outcomes are shown to be generally inconclusive (Ahmad et al., 2020). As the reasons, we assume that different countries have different endowments, histories, political and economic structures, development goals, institutions, cultures, energy policies, and others.

There are four different hypotheses on the energy-growth nexus, which are growth, conversation, feedback and neutrality (Ha \& Ngoc, 2020). First, the uni-directional causality running from 
energy consumption to economic growth. It is known as the "growth hypothesis". According to this, energy is a limiting factor to economic growth, so that shocks to energy supply will have a negative impact on economic growth (Ozturk, 2010). Second, the conservation hypothesis mentions that economic growth encourages the demand for energy consumption, i.e., uni-directional causality running from economic growth to energy consumption. Thus, energy consumption depends on the stage of economic growth (Islam et al., 2013). Third, the feedback hypothesis suggests a two-way causality between energy consumption and economic growth (Nazlioglu et al., 2014); these two impact one another. Forth, the neutrality hypothesis refers to no causality between energy consumption and economic growth, that is, energy consumption and economic growth are neutral with respect to each other (Ozturk, 2010; Nazlioglu et al., 2014).

An energy dependent economy can be represented by either the first or second or third hypothesis whose causal direction is positive. It implies that higher economic growth can be achieved by increasing energy consumption, or the former unsustainably increases the latter, or economic growth and energy consumption increase each other. Such a pattern of economic development is unsustainable, typically depending on the extensive use of non-renewable energy resources and causing the cumulative amount of environmental pollutants. (Note1) On the other hand, a more sustainable economy is associated with either the first or second or third hypothesis whose causal direction is negative, or the fourth hypothesis. In such a scenario, the government is expected to design energy and environmental conservation policies which can reduce the release of various environmental pollutants and ameliorate high dependency on fossil fuels, not adversely affecting economic performance (Sugiawan \& Managi, 2019).

\subsection{Sustainability}

While the debate on the energy-growth nexus is heating up, rapid exhaustion of natural resources and environmental pollution have been observed worldwide. In particular, global warming and climate change are considered as severe crises that require all nations to manage the level of energy consumption for reducing continuous and persistent pressure on the environment thus for achieving sustainable economic growth. Non-renewable energy sources-such fossil fuels as crude oil, coal, and natural gas - are known to emit a large amount of $\mathrm{CO}_{2}$ which is the main cause of global warming and climate change. While $\mathrm{CO}_{2}$ emissions have increased due to mounting energy consumption, there is an argument that the decline in $\mathrm{CO}_{2}$ emissions can be attributed to the fall in the energy consumption (Shahbaz et al., 2021). However, such a measure explicitly also has a negative impact on economic growth. Taking the nature of a long term relationship between economic growth, energy consumption and $\mathrm{CO}_{2}$ emissions into consideration, different countries may choose different strategies to fight against global warming and climate change.

In this context, the importance of energy and its sustainability is emphasized in United Nation's sustainable development goals (SDGs) that were adopted in 2015, as the most comprehensive global effort towards sustainable development (United Nations, 2021). There are seventeen 
SDGs which aim at reconciling economic and social goals with ecological ones. The SDGs are applied to all countries from the Global South to the Global North, covering economic and social goals as well as ecological sustainability challenges (Eisenmenger et al., 2020). In connection with the energy-growth nexus, such a pattern of economic growth, which targets to achieve the objectives of SDG 8 (decent work and economic growth) only, has been speculated to be unsustainable in nature (United Nations, 2019). On the other hand, the environmental and health-related hazards caused by fossil fuels have raised concern and discourse among nations (Etokakpan et al., 2020). Thus, high reliance on non-renewable energy requests nations to take concreate actions to attain the objectives of SDG 12 (responsible consumption and production) and SDG 13 (climate action).

\subsection{Environmental Kuznets Curve (EKC) Hypothesis}

As the solution to sustainable development, the Environmental Kuznets Curve (EKC) hypothesis was suggested in the literature. The EKC hypothesis is centered on an inverted-U interconnection between the level of $\mathrm{CO}_{2}$ emissions and the country's income (Adebayo and Akinsola, 2021), that is, initially, environmental pollution increases up to a certain level as income goes up, but after that level, it begins to decrease. (Note 2) Thus, we can detect a threshold at which the increasing trend in environmental degradation will be reversed; environmental quality deteriorates in the early stage of economic development but improves in the later stage as an economy develops. It is also described as environmental pressure increases faster than income in the early stage and slows down relative to GDP growth in higher income levels. (Note 3)

While the EKC debate has extended to whether economic growth would be the cause of environmental deterioration as well as the means to eventual environmental improvement, the interaction between economic growth, energy consumptions and $\mathrm{CO}_{2}$ emissions has been an active research area (Odugbesan and Rjoub, 2020). Several economists (e.g., Grossman and Krueger, 1991; Dinda, 2004; Stern, 2004) argued that an effective solution to environmental problems is economic growth; it is a significant condition that only when income grows, the effective environmental policies can be implemented (Dinda, 2004). Essentially, economic development is associated with energy consumption because higher growth is expected when more energy is consumed. Meanwhile, it is also equally likely that more efficient use of energy leading to a reduction in energy consumption needs a higher level of economic development. And as there is continuous and persistent demand for more energy sources putting pressure on the environment, better economic performance may be a catalyst for energy efficiency (Ang, 2008).

While there is a heated debate among economists, policymakers and researchers who design and formulate energy strategies, the primary motivation to conduct empirical studies on this issue is to find out evidence of the linkage between economic growth and environmental degradation. However, the empirical validity of the EKC hypothesis has been inconclusive for both developing and developed countries as empirical analysis is very sensitive to different countries, 
variables and time spans. (Note 4) So far, we do not see any single policy recommendation applicable for all countries to reduce pollution levels with rising economic growth.

\section{Empirical Strategy and Data}

We explain the empirical strategy to investigate Malaysia's energy-growth nexus and EKC hypothesis by referring to the following six-variable equations:

$$
\begin{aligned}
& E G_{t}=f_{1}\left(E N C_{t}, C_{T W O}, E G S Q_{t}, T_{O P}, F D I_{t}\right) \\
& E N C_{t}=f_{1}\left(E G_{t}, \text { COTWO }_{t}, E G S Q_{t}, T_{O P}, F D I_{t}\right) \\
& \operatorname{COTWO}_{t}=f_{1}\left(E G_{t}, E N C_{t}, E G S Q_{t}, \text { TOP }_{t}, F D I_{t}\right)
\end{aligned}
$$

Equations 1, 2 and 3 indicate that the Granger causality tests are conducted-in the framework of VECM and ARDL, respectively-to give interference to the causal linkage between the economic growth (EG, real per capita GDP), energy consumption (ENC, $\mathrm{kg}$ of oil equivalent per capita) and $\mathrm{CO}_{2}$ emissions (COTWO, metric tons per capita). While there are several pollutant variables (e.g., $\mathrm{SO}_{2}$ and $\mathrm{NO}_{\mathrm{x}}$ ), $\mathrm{CO}_{2}$ emissions are considered because they play a focal role in the current debate on environment protection and sustainable development (Lotfalipour et al., 2010), in particular on global warming and climate change. Importantly, the square of real per capita GDP (EGSQ) is incorporated to check the non-linearity of the energy-growth nexus and the validity of the EKC hypothesis. As the globalization variables, trade openness (TOP, exports + imports, per cent of GDP) and foreign direct investment (FDI, net inflows, per cent of GDP) are taken to address the omission-of-variable bias in estimation because Malaysia is one of highly globalized countries receiving a large volume of international trade and FDI. (Note 5)

To give interference to Malaysia's energy-growth nexus, the causalities of $\mathrm{ENC} \rightarrow \mathrm{EG}$ in equation 1 and $\mathrm{EG} \rightarrow \mathrm{ENC}$ in equation 2 are important; it can be either unilateral or bilateral having either a positive or a negative impact, or totally no causality. In addition, the causalities of $\mathrm{EG} \rightarrow \mathrm{ENC}$ and EGSQ $\rightarrow \mathrm{ENC}$ in equation 2 are related to checking the non-linearity of the energy-growth nexus. If both of these two causalities are statistically significant exhibiting different causal directions, we confirm evidence of non-linearity. As per the EKC hypothesis, we look at the coefficients of EG and EGSQ in equation 3. To prove the EKC hypothesis, the former is expected to be positive, and the latter to be negative, respectively. In this case, the presence of an inverted U-shaped curve is detected, that is, as the Malaysian economy grows, $\mathrm{CO}_{2}$ emissions also increase until a threshold level of real per capita GDP is reached after which $\mathrm{CO}_{2}$ emissions begin to decline. Moreover, we are interested in whether/how the globalization variables of TOP and FDI impact EG, ENC and $\mathrm{CO}_{2}$ in the three equations. The coefficients of TOP and FDI are assumed to be either positive or negative depending on the level of economic development. In general, if developing economies have less stringent environment regulations, greater TOP and 
more FDI are expected to increase environmental pollution (Sajeev and Kaur, 2020).

All the underlying variables are converted into logarithm. We use annual data series of the World Bank's World Development Indicators (WDI). The sample period covers 1971 to 2014, because of the availability of data series, in particular those of energy consumption and $\mathrm{CO}_{2}$ emissions which are available until 2014.

\section{Methodology}

\subsection{Initial Procedure}

In conducting time series analysis, we look for the presence of a long-run, steady-state equilibrium by employing vector autoregressive (VAR) with conditional error-correction models (ECMs). To this end, two cointegration techniques are available to us: the vector error correction model (VECM) of Johansen (1988) and the autoregressive distributed lag (ARDL) bounds test of Pesaran et al. (2001). Both of them can indicate a causal direction by the sign of each underlying variable's coefficient in the cointegrating space. Thus, it allows us to confirm whether the underlying variables of EG, ENC, COTWO, EGSQ, TOP and FDI have either positive or negative impact on each of them. In the VECM assessment, some underlying variables are treated as weakly exogenous variables that are taken into the cointegrating space but not as endogenous/dependent variables. While the VECM approach imposes a strict condition that all underlying variables must be $I(1)$ (integrated order one), the ARDL approach accepts the mixture of $I(0)$ (integrated order zero) and $I(1)$ variables in estimation. Considering these different characteristics, we use the two cointegration techniques to add more robustness to the analysis of Malaysia's energy-growth nexus and EKC hypothesis.

The estimation is started with unit root tests so as to check the stationarity/integration of each underlying variable. Unless non-stationary time series hold a long-run mean (i.e., their variance is time dependent), the presence of unit root causes inaccurate estimation. (Note 6) As far as the ARDL estimation is concerned, both $I(0)$ and $I(1)$ are okay but $I(2)$ (integrated order two) is unacceptable. Hence, to check whether each variable is either $I(0)$ or $I(1)$, we implement augmented Dickey-Fuller (ADF) test (Dickey and Fuller, 1979) and the Phillips and Perron (PP) test (Phillips and Perron, 1988). One invention of the present study is that, in addition to "intercept only" and "intercept and linear trend", the two unit root tests are also computed "intercept and structural break dummy 1997"as it is a well-known episode that the Asian financial crisis severely impacted Malaysia in 1997. We refer to the argument that researchers need to apply both the traditional and structural break unit root tests to make sure that the variables are not $I(2)$ (Menegaki, 2019).

\subsection{VECM Procedure}

We present the VECM system equations as follows: 


$$
\begin{aligned}
& {\left[\begin{array}{c}
\Delta E G_{t} \\
\Delta E N C_{t}
\end{array}\right]=\left[\begin{array}{l}
\alpha_{1 j} \\
\alpha_{2 j}
\end{array}\right]\left[\beta_{i 1} \beta_{i 2} \beta_{i 3} \beta_{i 4} \beta_{i 5} \beta_{i 6}\right]\left[\begin{array}{c}
E G_{t-1} \\
E N C_{t-1} \\
\operatorname{COTWO}_{t-1} \\
E G S Q_{t-1} \\
T O P_{t-1} \\
F D I_{t-1}
\end{array}\right]+\Gamma_{i j}\left[\begin{array}{c}
\Delta E G_{t-p} \\
\Delta E N C_{t-p} \\
\Delta \operatorname{COTWO}_{t-p} \\
\Delta E G S Q_{t-p} \\
\Delta T O P_{t-p} \\
\Delta F D I_{t-1}
\end{array}\right]+\left[\begin{array}{l}
\hat{u}_{1 t} \\
\hat{u}_{2 t}
\end{array}\right]} \\
& {\left[\begin{array}{c}
\Delta \operatorname{COTWO}_{t} \\
\Delta E G_{t}
\end{array}\right]=\left[\begin{array}{c}
\alpha_{1 j} \\
\alpha_{2 j}
\end{array}\right]\left[\beta_{i 1} \beta_{i 2} \beta_{i 3} \beta_{i 4} \beta_{i 5} \beta_{i 6}\right]\left[\begin{array}{c}
\operatorname{COTWO} O_{t-1} \\
E G_{t-1} \\
E N C_{t-1} \\
E G S Q_{t-1} \\
T O P_{t-1} \\
F D I_{t-1}
\end{array}\right]+\Gamma_{i j}\left[\begin{array}{c}
\Delta C O T W O_{t-p} \\
\Delta E G_{t-p} \\
\Delta E N C_{t-p} \\
\Delta E G S Q_{t-p} \\
\Delta T O P_{t-p} \\
\Delta F D I_{t-1}
\end{array}\right]+\left[\begin{array}{l}
\hat{u}_{1 t} \\
\hat{u}_{2 t}
\end{array}\right]}
\end{aligned}
$$

In each of the above VECM specifications, two variables are taken as the dependent/endogenous variables, and four variables are the weakly exogenous variables since it readily enables us to find a single cointegration relationship $(r=1)$ which provides more comprehensible analysis. Equation 4 is "Model I" in which EG and ENC are interchangeably treated as the dependent/endogenous variable, and COTWO, EGSQ, TOP and FDI are the weakly exogenous variables in the cointegrating space. Equation 5 is "Model II" where COTWO is the dependent variables, EG is the endogenous variable, and ENC, EGSQ, TOP and FDI are the weakly exogenous variables in the cointegrating space because the present study's objective is to give interference to Malaysia's EKC hypothesis (so that we do not analyse the case whose dependent variable is EG in Model II). The VECM estimation begins with the Johansen cointegration test to check the presence of the long-run relationship among six underlying variables. In performing the Johansen test, we seek a single cointegrating relationship $(r=1)$. Next, by normalizing each of EG and ENC/COTWO to one, we carry out two types of the Granger causality test. The first test is the weak exogeneity test that puts zero restrictions on $\alpha$, i.e. $H_{0}: \alpha_{i j}=0$; the rejection of the null hypothesis implies that there is a long-run causality formed by all the underlying variables in the system (Juselius and Johansen, 1992). The second test is the strong exogeneity test that is performed by imposing a restriction on both $\alpha$ and either of $\beta$ in the cointegrating space; i.e. $H_{0}$ : $\alpha_{i j} \beta_{i j}=0$ (Toda and Phillips, 1993). Based on the significant results of the two Granger causality tests, we give interference to Malaysia's energy-growth nexus and the EKC hypothesis in terms of the VECM analysis.

\subsection{ARDL Procedure}

The ARDL procedure is elucidated by the following system equations: 


$$
\begin{aligned}
& E G_{t}=\alpha_{i t}\left[\begin{array}{c}
E G_{t-1} \\
E N C_{t-1} \\
C O T W O_{t-1} \\
E G S Q_{t-1} \\
T O P_{t-1} \\
F D I_{t-1}
\end{array}\right]+\sum_{j=1}^{p-1} \theta_{1 j} \Delta E G_{t-j}+\sum_{j=1}^{p-1} \theta_{2 j} \Delta E N C_{t-j}+\sum_{j=1}^{p-1} \theta_{3 j} \Delta C O T W O_{t-j} \\
& +\sum_{j=1}^{p-1} \theta_{4 j} \Delta E G S Q_{t-j}+\sum_{j=1}^{p-1} \theta_{5 j} \Delta T O P_{t-j}+\sum_{j=1}^{p-1} \theta_{6 j} \Delta F D I_{t-j}\left[\begin{array}{l}
\hat{u}_{1 t} \\
\hat{u}_{2 t}
\end{array}\right]+i n p t+u_{i t}(6) \\
& \Delta E N C_{t}=\alpha_{i t}\left[\begin{array}{c}
E N C_{t-1} \\
E G_{t-1} \\
\operatorname{COTWO}_{t-1} \\
E G S Q_{t-1} \\
T O P_{t-1} \\
F D I_{t-1}
\end{array}\right]+\sum_{j=1}^{p-1} \theta_{1 j} \Delta E N C_{t-j}+\sum_{j=1}^{p-1} \theta_{2 j} \Delta E G_{t-j}+\sum_{j=1}^{p-1} \theta_{3 j} \Delta C O T W O_{t-j} \\
& +\sum_{j=1}^{p-1} \theta_{4 j} \Delta E G S Q_{t-j}+\sum_{j=1}^{p-1} \theta_{5 j} \Delta T O P_{t-j}+\sum_{j=1}^{p-1} \theta_{6 j} \Delta F D I_{t-j}\left[\begin{array}{l}
\hat{u}_{1 t} \\
\hat{u}_{2 t}
\end{array}\right]+i n p t+u_{i t}(7) \\
& \Delta C O T W O_{t}=\alpha_{i t}\left[\begin{array}{c}
\operatorname{COTWO}_{t-1} \\
E G_{t-1} \\
E N C_{t-1} \\
E G S Q_{t-1} \\
T O P_{t-1} \\
F D I_{t-1}
\end{array}\right]+\sum_{j=1}^{p-1} \theta_{1 j} \Delta \operatorname{COWTO}_{t-j}+\sum_{j=1}^{p-1} \theta_{2 j} \Delta E G_{t-j}+\sum_{j=1}^{p-1} \theta_{3 j} \Delta E N C_{t-j} \\
& +\sum_{j=1}^{p-1} \theta_{4 j} \Delta E G S Q_{t-j}+\sum_{j=1}^{p-1} \theta_{5 j} \Delta T O P_{t-j}+\sum_{j=1}^{p-1} \theta_{6 j} \Delta F D I_{t-j}\left[\begin{array}{l}
\hat{u}_{1 t} \\
\hat{u}_{2 t}
\end{array}\right]+i n p t+u_{i t}(8)
\end{aligned}
$$

Equations 6, 7 and 8 are "Models III, IV and V" in which EG, ENC and COTWO are treated as the dependent variables, respectively. Firstly, we implement the bounds test, which is based on $F$-statistics, so as to confirm the existence of cointegration between the underlying variables which are either $I(0)$ or $I(1)$ (i.e., not $I(2))$. The null hypothesis of the bounds test is either accepted or rejected depending on the valuation of $F$-statistics. When computed $F$-statistics are greater than upper bound critical values, the null hypothesis is rejected and it is judged that there is a cointegrating relationship between the underlying variables. In another case, when computed $F$-statistics locate within lower and upper bound critical values, the result is inconclusive so that we need to look at the results of unit root tests. Secondly, we determine the optimal lag order of each variable by referring to either the Akaike information criterion (AIC) or the R-bar squared criterion. (Note 7) Thirdly, both the weak and strong exogeneity tests are carried out to give interference in the ARDL analysis. The weak exogeneity test addresses the null hypothesis of $H_{0}$ : 
$\alpha_{i}=0$ to check the evidence of a long-run causality or the significance of the ECT coefficient. Meanwhile, the ARDL strong exogeneity test is based on a different concept from that of the VECM estimation. It examines the nulls of $H_{0}$ : all $\alpha_{j}=\theta_{i j}$ 's $=0$. Thus, the overall (long-run + short-run) causality in the system is identified by the strong exogeneity test, irrespective of time spans in the ARDL estimation (Charemza \& Deadman, 1997).

\subsection{Structural Break Dummy}

Importantly, referring to Johansen et al. (2000) and Pesaran and Pesaran (2009) who suggest a technique taking the element of structural break-in the form of level shift dummy-into the cointegration analysis, we incorporate the structural break dummy (SBD). The dummy variable is 0 before 1997 and 1 after that year in both the VECM and ARDL estimations due to the same reason as stated for the unit root tests, that is, Malaysia experienced a critical financial crisis in 1997, which might be very influential for structuring the cointegration relationship between the underlying variables. (Note 8)

\section{Empirical Results}

\subsection{Unit Root Tests}

In Table 1, the ADF and PP test results of Malaysia's six underlying variables are reported. For each variable, the judgement is different depending on either "intercept only" or "intercept and trend" or "intercept and structural break dummy" in the two tests. For example, trade openness is judged as $I(1)$ in the PP test but not so in the ADF test (possibly be $I(2)$ ). Likewise, foreign direct investment is $I(1)$ in the ADF test, but it is $I(0)$ in the PP test. Looking at these statistics as a whole, we argue that all the variables are not perfectly okay but is fairly acceptable for the VECM and ARDL cointegration analysis. Rather, such diverse unit root results validates the simultaneous use of the VECM and ARDL techniques to put more robustness to the present study. 
Table 1. ADF and PP Test Results $(k=4)$

\begin{tabular}{|c|c|c|c|c|c|c|c|}
\hline & $\underline{\mathrm{ADF} \text { Test }}$ & & & & $\underline{\text { PP Test }}$ & & \\
\hline & Inpt. only & $\begin{array}{l}\text { Inpt.. } \\
\text { Trend }\end{array}$ & $\&$ & $\begin{array}{l}\text { Inpt. } \\
\text { SBD }\end{array}$ & Inpt. only & $\begin{array}{l}\text { Inpt. } \\
\text { Trend }\end{array}$ & $\begin{array}{l}\text { Inpt. } \\
\text { SBD }\end{array}$ \\
\hline EG & -1.1819 & -2.4545 & & -2.6492 & -1.5443 & $-4.3963 * * *$ & -2.7210 \\
\hline$\Delta \mathrm{EG}$ & $-3.0433 * *$ & -3.0480 & & $-3.0344 *$ & $-9.9286^{* * *}$ & $\begin{array}{l}-10.0991 * * \\
*\end{array}$ & $\begin{array}{l}-9.2789 * * \\
*\end{array}$ \\
\hline COTWO & -1.1390 & -1.9930 & & -2.2965 & -.79134 & -2.1397 & -2.1148 \\
\hline $\begin{array}{l}\Delta \mathrm{COTW} \\
\mathrm{O}\end{array}$ & $-2.5773 *$ & -2.5697 & & -2.6372 & $-7.6027 * * *$ & $-7.5500 * * *$ & $\begin{array}{l}-8.3066^{* *} \\
*\end{array}$ \\
\hline ENC & -2.1978 & -1.1597 & & -2.3641 & -1.2020 & -1.8164 & -2.0481 \\
\hline$\triangle \mathrm{ENC}$ & -2.4081 & -3.0919 & & -3.0430 & $-7.1445^{* * *}$ & $-7.5268 * * *$ & $\begin{array}{l}-7.3321 * * \\
*\end{array}$ \\
\hline EGSQ & -.78872 & -2.5332 & & -2.5828 & -1.0760 & $-4.5521 * * *$ & -2.6016 \\
\hline$\Delta \mathrm{EGSQ}$ & $-3.0589 * *$ & -3.0187 & & -3.0130 & $\begin{array}{l}-10.3930 * * \\
*\end{array}$ & $\begin{array}{l}-10.3537 * * \\
*\end{array}$ & $\begin{array}{l}-9.5540 * * \\
*\end{array}$ \\
\hline TOP & -1.8122 & .16085 & & -1.4781 & -1.7789 & .32160 & -1.6573 \\
\hline$\Delta \mathrm{TOP}$ & -1.5502 & -2.2066 & & -2.5749 & $-5.1160 * * *$ & $-5.9307 * * *$ & $\begin{array}{l}-6.0758 * * \\
*\end{array}$ \\
\hline FDI & $-2.8589^{*}$ & -2.9841 & & $-3.2063^{*}$ & $-5.5705 * * *$ & $-5.5587 * * *$ & $\begin{array}{l}-5.8999 * * \\
*\end{array}$ \\
\hline$\Delta \mathrm{FDI}$ & $\begin{array}{l}-3.9531 * * \\
*\end{array}$ & $-3.8632 * *$ & & $-4.0781 * * *$ & $\begin{array}{l}-12.4712 * * \\
*\end{array}$ & $\begin{array}{l}-12.2863 * * \\
*\end{array}$ & $\begin{array}{l}-9.8467 * * \\
*\end{array}$ \\
\hline
\end{tabular}

Notes. (***) 1\%,(**) 5\% and $(*) 10 \%$ level of significance. The critical values are simulated with 1000 replications. 


\subsection{VECM Results}

Table 2 shows the results of the Johansen cointegration test. Model I, whose dependent/endogenous variables are EG and ENC and selected lag order is four, addresses the energy-growth nexus. The test result indicates that there is a single cointegration $(r=1)$ at the $1 \%$ significance level. On the other hand, for Model II, whose dependent variable is COTWO and endogenous variable is EG, and selected lag order is two, we also find a single cointegration $(r=$ 1) at the $1 \%$ significance level, so that it allows us to examine the EKC hypothesis. Before proceeding, we see the diagnostic test statistics in Table 3. According to them, since both Models I and II are free from such estimation problems of autocorrelation, non-normality and heteroscedasticity, the VECM analysis is considered as statistically acceptable.

Table 2. Johansen Cointegration Test Results

\begin{tabular}{lllll}
\hline Model I (VECM) & $k=4$ & & \\
$\underline{\text { Dep./End. variable }}$ & $\underline{\text { Weakly exo. variables }}$ & $\underline{\text { Det. components }}$ & $\underline{\text { Null }}$ & $\underline{p \text {-value }}$ \\
EG & COTWO, EGSQ & Intercept (rest.) & $r=0$ & $0.000^{* * *}$ \\
ENC & TOP, FDI & SBD (rest.) & $r<=1$ & 0.319 \\
\hline Model II (VECM) & $k=2$ & & & \\
Dep. variable & Weakly exo. variables & $\underline{\text { Det. components }}$ & $\underline{\text { Null }}$ & $\underline{p \text {-value }}$ \\
COTWO & ENC, EGSQ & Intercept (rest.) & $r=0$ & $0.005^{* * *}$ \\
$\underline{\text { End. variable }}$ & TOP, FDI & SBD (rest.) & $r<=1$ & 0.217 \\
EG & & & & \\
\hline
\end{tabular}

Notes. (***) 1\% level of significance. The results are based on critical values simulated with 400 random walks and 2500 replications. 
Table 3. VECM Diagnostic Test Results

\begin{tabular}{|c|c|c|c|}
\hline Test & & Model I & Model II \\
\hline \multirow[t]{3}{*}{$\underline{\text { Autocorrelation }}$} & Ljung-Box(11) & $40.398[0.036]$ & $73.042[0.000]$ \\
\hline & LM(1) & $9.748[0.045]$ & $1.823[0.768]$ \\
\hline & LM(2) & $2.418[0.659]$ & $1.676[0.795]$ \\
\hline Normality & & $0.767[0.943]$ & $8.252[0.083]$ \\
\hline \multirow[t]{2}{*}{$\underline{\mathrm{ARCH}}$} & $\mathrm{LM}(1)$ & $9.170[0.422]$ & $6.946[0.643]$ \\
\hline & LM(2) & $14.354[0.706]$ & $8.413[0.972]$ \\
\hline
\end{tabular}

Notes. The results are based on $X_{2}$ statistics. $P$-values are given in parentheses.

Tables 4 and 5 show the VECM causality test results (1. Cointegrating vector; 2. Weakly exogenous test; and 3. Strong exogeneity test) of Models I and II, respectively. First of all, since the sign of each coefficient in the cointegrating vector exhibits the causal direction of each underlying variable, the coefficient of EG/ENC/COTWO is normalized to one. Thus, the direction of each underlying variable is identified with respect to each dependent variables, i.e. whether one variable is either positive or negative to economic growth/energy consumption $/ \mathrm{CO}_{2}$ emissions by checking each variable's sign in the cointegrating vector (the direction of each variable is extracted in the third column of the tables). Subsequently, each model's " $\alpha$ " (the error correction term (ECT) coefficient) shows the speed of adjustment back to the long-run equilibrium whenever there is a deviation from a steady state in the system. Therefore, the ECT coefficient is expected to be statistically significant with a negative sign. According to the weakly exogeneity statistics in Tables 4 and 5, all three ECTs possess a negative sign. Model I's two ECTs are the 1\% level significant. Meanwhile, in the case of Model II, when COTWO is the dependent variable, the ECT is marginally significant at the $10 \%$ level.

\subsubsection{VECM Energy-Growth Nexus}

In Table 4, the strong exogeneity statistics of Model I, which are relevant to the energy-growth nexus, show a negative bilateral causality between economic growth and energy consumption (EG↔ENC(-)) as well as a positive causality from the square of economic growth to energy consumption (EGSQ $\rightarrow \mathrm{ENC}(+)$ ). Combining the two causal results, we highlight the evidence of non-linearity in Malaysia' s energy-growth nexus, that is, it is bilateral in a linear specification, 
but after going through a threshold, as the economy grows, more energy is consumed. In the energy-growth nexus estimation, since $\mathrm{CO}_{2}$ is negative for economic growth at the $1 \%$ significance level, more $\mathrm{CO}_{2}$ emissions are unsuitable for the Malaysian economy. As far as the globalization variables in Malaysia's energy-growth nexus are concerned, trade openness is positive for both economic growth and energy consumption at the $1 \%$ significance level, whereas FDI is negative for economic growth at the $1 \%$ significance level but a meaningful statistic of FDI causing energy consumption is not detected.

\subsubsection{VECM EKC Hypothesis}

In Table 5, according to the strong exogeneity results of Model II, which are relevant to the EKC hypothesis (i.e., COTWO is the dependent variable), economic growth is negative for $\mathrm{CO}_{2}$ emissions, whereas the square of economic growth is positive for $\mathrm{CO}_{2}$ emissions. (Note 9) Joining the two causal results, we observe that Malaysia's EKC is U-shaped, that is, in the initial stage, as the Malaysian economy grows, less $\mathrm{CO}_{2}$ is released; after a turning point, however, as the economy grows, more $\mathrm{CO}_{2}$ emissions are observed. We mention other Model II causality results: 1) energy consumption is positive for $\mathrm{CO}_{2}$ emissions at the $10 \%$ significance level; 2) trade openness increases $\mathrm{CO}_{2}$ emissions at the 1\% significance level; and 3) FDI's impact on $\mathrm{CO}_{2}$ emissions is insignificant.

Table 4. VECM Results (Model I)

Model I (Dependent variable: EG)

1. Cointegrating vector

$E G=-2.707 E N C-1.567 C O T W O+0.542 E G S Q+1.668 T O P-0.337 F D I-0.685 \mathrm{SBD}+4.461$

2. Weakly exogenous test

$\underline{\text { ECT coefficient }}$

$\alpha=-0.029$

3. Strong exogeneity test

$\underline{\text { Regressors }}$

ENC \& ECT(-1) $\underline{\text { Result }}$

$\operatorname{CHISQR}(2)=38.957[0.000]^{* * *}$ $\underline{\text { Direction }}$

Negative 
COTWO \& ECT(-1)

EGSQ \& ECT(-1)

TOP \& ECT(-1)

FDI \& ECT(-1)

$$
\operatorname{CHISQR}(2)=19.620[0.000]]^{* * *} \quad \text { Negative }
$$

$\operatorname{CHISQR}(2)=16.653[0.000]^{* * *} \quad$ Positive

$\operatorname{CHISQR}(2)=23.602[0.000]^{* * *} \quad$ Positive

Negative

Model I (Dependent variable: ENC)

1. Cointegrating vector

$E N C=-0.369 E G-0.579 C O T W O+0.200 E G S Q+0.616 T O P-0.124 F D I-0.253 S B D+1.648$

2. Weakly exogenous test

$\underline{\text { ECT coefficient }}$

$\alpha=-0.721$

3. Strong exogeneity test

$\underline{\text { Regressors }}$

EG \& ECT(-1)

COTWO \& ECT(-1)

EGSQ \& ECT(-1)

TOP \& ECT(-1)

FDI \& ECT(-1) $§$ $\underline{\text { Result }}$

$\operatorname{CHISQR}(1)=19.243[0.000]^{* * *}$

Notes. $(* * *) 1 \%$ level of significance. ( $($ ) Since the chosen normalization invalidates calculation of the "standard error" for beta, the result is not provided. 
Table 5. VECM Results (Model II)

Model II (Dependent variable: COTWO)

1. Cointegrating vector

COTWO $=-12.059 E G+0.602 E N C+1.174 E G S Q+1.069 T O P-0.059 F D I-0.466 S B D+22.659$

2. Weakly exogenous test

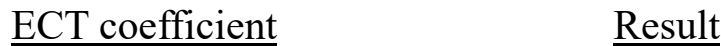

$\alpha=-0.199 \quad \operatorname{CHISQR}(1)=2.835[0.092]^{*}$

3. Strong exogeneity test

$\underline{\text { Regressors }} \quad \underline{\text { Result }} \quad$ Direction

EG \& ECT(-1) CHISQR $(2)=16.094[0.000]^{* * *} \quad$ Negative

ENC \& ECT(-1) CHISQR(2) $=4.747[0.093]^{*} \quad$ Positive

EGSQ \& ECT(-1) CHISQR $(2)=15.470[0.000]^{* * *} \quad$ Positive

TOP \& ECT(-1) CHISQR(2) $=12.141[0.002]^{* * *} \quad$ Positive

FDI \& ECT(-1) CHISQR(2) $=4.546[0.103] \quad$ Negative

Notes. (***) 1\% level and (*) 10\% level of significance.

\subsection{ARDL Results}

The ARDL bounds test confirms a cointegration relationship in the three models, in which we treat EG (Model III), ENC (Model IV) and COTWO (Model V) as the dependent variables, respectively. In performing the ARDL bounds test, it is important to select each underlying variable's lag order. While the lag orders of Models III and IV are specified by the Akaike criterion, those of Model V are given by the R-bar squared criterion. Table 6 reveals that the existence of cointegration is validated for all the models at the 5\% significance level. According to the diagnostic statistics in Table 7, as all the ARDL models are free from serious estimation problems of autocorrelation, functional form (expect for that of Model III), non-normality and 
heteroscedasticity, we consider the ARDL analysis as statistically acceptable to precede.

Table 6. ARDL Bounds Test Results ( $F$-statistics, $k=2)$

Model III

$\begin{array}{lllll}\text { Dep. variable } & \underline{\text { End. variables }} & \text { Selected lag orders } & \underline{\text { Det. components }} & \text { Statistic } \\ \text { EG } & \text { ENC,COTWO } & (2,0,0,2,2,0) & \text { Intercept (rest.) } & 5.4067 * * \\ & \text { EGSQ,TOP,FDI } & \text { SBD (rest.) } & \end{array}$

Model IV

$\underline{\text { Dep. variable } \quad \underline{\text { End. variables }} \text { Selected lag orders } \underline{\text { Det. components }} \text { Statistic }}$

ENC EG,COTWO $(1,2,1,1,0,1) \quad$ Intercept (rest.) $\quad 4.3945^{* *}$

EGSQ,TOP,FDI $\quad$ SBD (rest.)

Model V

Dep. variable End. variables $\quad \underline{\text { Selected lag orders }}$ Det. components $\underline{\text { Statistic }}$

COTWO EG,ENC $\quad(2,0,1,0,2,0) \quad$ Intercept (rest.) $\quad 4.8744 * *$

EGSQ,TOP,FDI $\quad$ SBD (rest.)

Notes. (**) 5\% of significance. The selected lag orders are given as (EG, ENC, COTWO, EGSQ, TOP, FDI) for Model III, (ENC, EG, COTWO, EGSQ, TOP, FDI) for Model IV, and as (COTWO, EG, ENC, EGSQ, TOP, FDI) for Model V, respectively. The lag orders of Models III and IV are given by the Akaike criterion, whereas that of Model V is by the R-bar squared criterion. 
Table 7. ARDL Diagnostic Test Results

\begin{tabular}{llll}
\hline & Model III & Model IV & Model V \\
\hline Serial correlation & $0.0942[.759]$ & $0.5150[.473]$ & $1.0554[.304]$ \\
Functional form & $41.851[.000]$ & $0.1343[.714]$ & $0.8683[.351]$ \\
Normality & $0.2569[.879]$ & $1.3628[.506]$ & $0.0694[.966]$ \\
Heteroscedasticity & $0.0275[.868]$ & $2.1576[.142]$ & $0.1328[.716]$ \\
\hline
\end{tabular}

Tables 8, 9 and 10 present the ARDL results (1. Cointegrating vector; 2. Weakly exogenous test; and 3. Strong exogeneity test) of Models III, IV and V, respectively. In the first line of each table, the identified cointegrating vectors, in which the coefficient of EG/ENC/COTWO is normalized to one, are provided in order to confirm each underlying variable's causal direction to the dependent variable. In the second line, the weakly exogeneity statistics show that each model's ECT coefficient is significant at the $1 \%$ level having a negative sign.

\subsubsection{ARDL Energy-Growth Nexus}

To give interference to Malaysia's energy-growth nexus in terms of the ARDL analysis, we refer to the strong exogeneity results of Models III and IV in Tables 8 and 9. From these statistics, we detect a positive bilateral relationship economic growth and energy consumption $(\mathrm{EG} \leftrightarrow \mathrm{ENC}(+))$, and a negative causality from the square of economic growth to energy consumption $(\mathrm{EGSQ} \rightarrow \mathrm{ENC}(-))$. Thus, the evidence of non-linearity in Malaysia's energy-growth nexus is confirmed, that is, it is bilateral in a linear specification, but after going through a threshold, as the economy grows, less energy is consumed. In assessing the Malaysian energy-growth nexus, we also find that $\mathrm{CO}_{2}$ emissions are negative for economic growth at the $1 \%$ significance level in Model III, so that more $\mathrm{CO}_{2}$ emissions are not good for economic growth. In relevant to the globalization variables, trade openness is positive for economic growth at the $1 \%$ significance level and negative for energy consumption at the 1\% significance level, whereas FDI is negative for economic growth at the $1 \%$ significance level and positive for energy consumption at the $1 \%$ significance level.

\subsubsection{ARDL EKC Hypothesis}

In Table 10, as far as Malaysia's EKC hypothesis is concerned, the strong exogeneity estimates of Model $\mathrm{V}$ show that economic growth is negative for $\mathrm{CO}_{2}$ emissions but the square of economic growth is positive for $\mathrm{CO}_{2}$ emissions. Thus, in the ARDL analysis, we find out a U-shaped EKC is observed in Malaysia, that is, in the initial stage, as the Malaysian economy 
grows, less $\mathrm{CO}_{2}$ is released; but after a turning point, as the economy grows, more $\mathrm{CO}_{2}$ emissions are witnessed. Other causality results show that: 1) more energy consumption increases $\mathrm{CO}_{2}$ emissions at the $1 \%$ significance level; 2) trade openness is positive for $\mathrm{CO}_{2}$ emissions at the $1 \%$ significance level; and 3) FDI is insignificant for $\mathrm{CO}_{2}$ emissions.

Table 8. ARDL Results (Model III)

Model III (Dependent variable: EG)

1. Cointegrating vector

$E G=0.020 E N C-0.065 C O T W O+0.098 E G S Q+0.095$ TOP $-0.008 F D I-0.036 \mathrm{SBD}+2.039$

2. Weakly exogenous test

$\underline{\text { ECT coefficient }} \underline{\text { Result }}$

$\alpha=-0.562 \quad \operatorname{CHSQR}(1)=14.1731[0.000]^{* * *}$

3. Strong exogeneity test

$\underline{\text { Regressors }}$

$\underline{\text { Result }}$

Direction

$\triangle \mathrm{ENC} \& \mathrm{ECT}(-1)$

$\operatorname{CHSQR}(2)=21.0725[.000]^{* * *} \quad$ Positive

$\triangle$ COTWO \& ECT(-1)

$\operatorname{CHSQR}(2)=14.6791[.001]^{* * *} \quad$ Negative

$\triangle$ EGSQs \& ECT(-1)

CHSQR(3) $=3155.8[.000]^{* * *} \quad$ Positive

$\triangle$ TOPs \& ECT(-1)

CHSQR(3) $=26.8330[.000]^{* * *} \quad$ Positive

$\Delta$ FDI \& ECT(-1)

$\operatorname{CHSQR}(2)=33.5618[.000]^{* * *}$

Negative

Notes. $(* * *) 1 \%$ level of significance. 
Table 9. ARDL Results (Model IV)

Model IV (Dependent variable: ENC)

1. Cointegrating vector

$E N C=7.131 E G+0.211 C O T W O-0.595 E G S Q-0.322 T O P+0.029 F D I+0.180 S B D-12.420$

2. Weakly exogenous test

ECT coefficient

$\alpha=-0.559$

3. Strong exogeneity test

$\underline{\text { Regressors }}$

$\Delta$ EGs \& ECT $(-1)$

$\triangle$ COTWO \& ECT(-1)

$\triangle$ EGSQ \& ECT(-1)

$\Delta \mathrm{TOP} \& \mathrm{ECT}(-1)$

$\Delta \mathrm{FDI} \& \mathrm{ECT}(-1)$ $\underline{\text { Result }}$

$\operatorname{CHSQR}(3)=20.3578[.000]^{* * *}$

$\operatorname{CHSQR}(2)=32.4464[.000]^{* * *}$

$\operatorname{CHSQR}(2)=20.2605[.000]]^{* * *}$

$\operatorname{CHSQR}(2)=22.6874[.000]^{* * *}$

$\operatorname{CHSQR}(2)=21.4775[.000]^{* * *}$
Direction

Positive

Positive

Negative

Negative

Positive

Notes. $(* * *) 1 \%$ level of significance. 
Table 10. ARDL Results (Model V)

Model V (Dependent variable: COTWO)

1. Cointegrating vector

COTWO $=-7.372 E G+0.379 E N C+0.770 E G S Q+0.875$ TOP $-0.045 F D I-0.442 S B D+11.84$

2. Weakly exogenous test

$\underline{\text { ECT coefficient }} \quad \underline{\text { Result }}$

$\alpha=-0.585$

$\operatorname{CHSQR}(1)=19.933[.000]^{* * *}$

3. Strong exogeneity test

$\underline{\text { Regressors }} \quad \underline{\text { Result }} \quad$ Direction

$\triangle \mathrm{EG} \& \mathrm{ECT}(-1) \quad \operatorname{CHSQR}(2)=23.4084[.000]^{* * *} \quad$ Negative

$\triangle \mathrm{ENC} \& \mathrm{ECT}(-1) \quad \operatorname{CHSQR}(2)=32.8617[.000]^{* * *} \quad$ Positive

$\triangle E G S Q \&$ ECT(-1) CHSQR $(2)=23.8273[.000]^{* * *} \quad$ Positive

$\triangle \mathrm{TOPs} \& \mathrm{ECT}(-1) \quad \operatorname{CHSQR}(3)=23.0357[.000]^{* * *} \quad$ Positive

$\Delta$ FDI \& ECT(-1) CHSQR $(2)=21.1511[.000]^{* * *} \quad$ Negative

Notes. $(* * *) 1 \%$ level of significance.

\section{Conclusions and Policy Implications}

We investigated Malaysia's energy-growth nexus and EKC hypothesis over the period 1971-2014 by taking the globalization variables of trade openness and foreign direct investment (FDI) and the structural break dummy of the Asian financial crisis of 1997 into estimation. In Table 11 the main findings of the present study are summarized.

Firstly, we highlight different results for Malaysia's energy-growth nexus between the two cointegration approaches. The VECM results show that the causal linkage is "negative and bilateral" (EG↔ENC(-)), whereas the square of economic growth releases a positive impact on 
energy consumption (EGSQ $\rightarrow \mathrm{ENC}(+))$. According to the ARDL results, it is "positive and bilateral" ( $\mathrm{EG} \leftrightarrow \mathrm{ENC}(+))$, but the square of economic growth is negative for energy consumption $(\mathrm{EGSQ} \rightarrow \mathrm{ENC}(-))$. Taking these findings into consideration, we consider that although the presence of the energy-growth nexus in Malaysia was statistically confirmed, it has not been fully established yet. Ideally, "the less energy consumption, the higher economic growth" (as indicated by the ARDL estimation) is desired for sustainable development in the future. Secondly, as per the EKC hypothesis, both the VECM and ARDL results provided the same conclusion, that is, in the initial stage, as the higher economic growth, the less $\mathrm{CO}_{2}$ emissions, but after a threshold, the higher economic growth, the more $\mathrm{CO}_{2}$ emissions; it indeed exhibits a "not eco-friendly pattern" in Malaysia. Thirdly, we also confirmed the effects of the globalization variables. Trade openness is positive for economic growth as well as for $\mathrm{CO}_{2}$ emissions in both the VECM and ARDL estimations. Not to mention, such a pattern of development is typically unsustainable. As far as FDI is concerned, it is positive for economic growth in the VECM estimation but it is negative in the ARDL estimation. FDI is positive for energy consumption and negative for $\mathrm{CO}_{2}$ emissions in the ARDL estimation, whereas no significant estimate was detected for energy consumption and $\mathrm{CO}_{2}$ emissions in the VECM estimation.

As our policy implication, we argue that Malaysia needs to surely transform into a less-energy-consumption economy while attaining higher economic growth. So far, as indicated by our findings, it is uncertain whether Malaysia will follow the above argument. To achieve sustainable development, more precisely, to attain the objectives of SDG 12 (responsible consumption and production) and SDG 13 (climate action), policymakers are required to form national development strategies how to introduce and generalize renewable energy resources (e.g., hydropower, solar power and wind power) which are very necessary to protect the environment. At the same time, policymakers should evaluate and apply the impact of globalization on Malaysia's sustainable development. It is important to export and import such products that contribute to environmental conservation, or to attract a large amount of FDI that can bring environmental protection technologies to the country. Thus, we hope that Malaysia will be ahead of other countries, leaving from such an undesirable scenario that developing countries are more likely to attract polluting industries due to lower environmental standards.

Finally, while the sample period of our Malaysian study was limited to 1971-2014 (in fact it was the best available period for us), we will investigate the energy-growth nexus and EKC hypothesis in emerging economies by incorporating the impact of the COVID-19 crisis for the future study. 
Table 11. Summary of Malaysia's Energy-Growth Nexus and EKC hypothesis Results

1. Energy-growth nexus

VECM

$\mathrm{EG} \leftrightarrow \mathrm{ENC}(-)$

$\mathrm{EGSQ} \rightarrow \mathrm{ENC}(+)$ $\underline{\text { ARDL }}$

$\mathrm{EG} \leftrightarrow \mathrm{ENC}(+)$ (positive \& bilateral)

$\mathrm{EGSQ} \rightarrow \mathrm{ENC}(-)$

2. EKC hypothesis

VECM

U-shaped

$[\mathrm{EG} \rightarrow \mathrm{COTWO}(-) ; \mathrm{EGSQ} \rightarrow \mathrm{COTWO}(+)]$
ARDL

U-shaped

$[\mathrm{EG} \rightarrow \mathrm{COTWO}(-) ; \mathrm{EGSQ} \rightarrow \mathrm{COTWO}(+)]$

3. Globalization

a. Trade openness

VECM

$\mathrm{TOP} \rightarrow \mathrm{EG}(+)$

$\mathrm{TOP} \rightarrow \mathrm{ENC}(+)$

$\mathrm{TOP} \rightarrow \mathrm{COWTO}(+)$

b. FDI

$\underline{\text { VECM }}$

$\mathrm{FDI} \rightarrow \mathrm{EG}(+)$

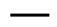

$\underline{\text { ARDL }}$

$\mathrm{TOP} \rightarrow \mathrm{EG}(+)$

$\mathrm{TOP} \rightarrow \mathrm{ENC}(-)$

$\mathrm{TOP} \rightarrow \mathrm{COWTO}(+)$

$\underline{\text { ARDL }}$

$\mathrm{FDI} \rightarrow \mathrm{EG}(-)$

$\mathrm{FDI} \rightarrow \mathrm{ENC}(+)$

$\mathrm{FDI} \rightarrow \mathrm{COWTO}(-)$ 


\section{Acknowledgments}

I thank my wife, Hidemi Fukuda, for her daily support to my research and many others.

\section{References}

Adebayo, T. S., \& Akinsola, G. D. (2021). Investigating the Causal Linkage among Economic Growth, Energy Consumption and $\mathrm{CO}_{2}$ Emissions in Thailand: An Application of the Wavelet Coherence Approach. International Journal of Renewable Energy Development, 10(1), 17-26. https://doi.org/10.14710/ijred.2021.32233

Ahmad, N., Aghdam, R. F., Butt, I., \& Naveed, A. (2020). Citation-Based Systematic Literature Review of Energy-Growth Nexus: An Overview of the Field and Content Analysis of the Top 50 Influential Papers. Energy Economics, 86(February 2020), 104642. https://doi.org/10.1016/j.eneco.2019.104642

Ang, J. B. (2008). Economic Development, Pollutant Emissions and Energy Consumption in Malaysia. Journal of Policy Modeling, $30(2), \quad$ 271-278. https://doi.org/10.1016/j.jpolmod.2007.04.010

Arif, A., Sadiq, M., Shabbir, M. S., Yahya, G., Zamir, A., \& Lopez, L. B. (2020). The Role of Globalization in Financial Development, Trade Openness and Sustainable Environmental-Economic Growth: Evidence from Selected South Asian Economies. Journal of Sustainable Finance and Investment. https://doi.org/10.1080/20430795.2020.1861865

Bekhet, H. A., \& Yasmin, T. (2017). Dynamic Linkages among Financial Development, Economic Growth, Energy Consumption, $\mathrm{CO}_{2}$ Emissions and Gross Fixed Capital Formation Patterns in Malaysia. International Journal of Business and Globalisation, 8(4), 493-523. https://doi.org/10.1504/IJBG.2017.084355

Charemza, W. W., \& Deadman, D. F. (1997). New Directions in Econometric Practice (2nd ed.). Edward Elgar.

Dickey, D. A., \& Fuller, W. A. (1979). Distribution of the Estimators for Autoregressive Time Series with a Unit Root. Journal of the American Statistical Association, 74(366), 427-431. https://doi.org/10.1080/01621459.1979.10482531

Dinda, S. (2004). Environmental Kuznets Curve Hypothesis: A Survey. Ecological Economics, 49(4), 431- 455. https://doi.org/10.1016/j.ecolecon.2004.02.011

Eisenmenger, N., Pichler, M., Krenmayr, N., Noll, D., Plank, B., Schalmann, E., Wandl, M., \& Gingrich, S. (2020). The Sustainable Development Goals Prioritize Economic Growth over Sustainable Resource Use: A Critical Reflection on the SDGs from a Socio-Ecological $\begin{array}{llrl}\text { Perspective. } & \text { Sustainability } & \text { Science, } & 15(4),\end{array}$ https://doi.org/10.1007/s11625-020-00813-X

Etokakpan, M. U., Solarin, S. A., Yorucu, V., Bekun, F. V., \& Sarkodie, S. A. (2020). Modeling Natural Gas Consumption, Capital Formation, Globalization, $\mathrm{CO}_{2}$ Emissions and Economic Growth Nexus in Malaysia: Fresh Evidence from Combined Cointegration and Causality Analysis. Energy Strategy Reviews, 31(September 2020), 1-11. 
https://doi.org/10.1016/j.esr.2020.100526

Fukuda, T. (2020). Finance-Growth Nexus and Globalization in Brazil, India, Philippines, Thailand, and Turkey: Evidence from VECM Cointegration Analysis. Journal of Economics and Financial Analysis, 4(1), 55-77. http://dx.doi.org/10.1991/jefa.v4i1.a32

Grossman, G. M., \& Krueger, A. B. (1991). Environmental Impacts of a North American Free Trade Agreement (NBER Working papers series, No. 3914). National Bureau of Economic Research, Cambridge, United States.

Ha, N. M., \& Ngoc, B. H. (2020). Revisiting the Relationship between Energy Consumption and Economic Growth Nexus in Vietnam: New Evidence by Asymmetric ARDL Cointegration. Applied Economic Letters, 28(12), 978-984. https://doi.org/10.1080/13504851.2020.1789543

Islam, F., Shahbaz, M., Ahmed, A. U., \& Alam, M. M. (2013). Financial Development and Energy Consumption Nexus in Malaysia: A Multivariate Time Series Analysis. Economic Modelling, 30(January 2013), 435-441. https://doi.org/10.1016/j.econmod.2012.09.033

Johansen, S. (1988). Statistical Analysis of Cointegration Vectors. Journal of Economic Dynamics and Control, 12(2-3), 231-254. https://doi.org/10.1016/0165-1889(88)90041-3

Johansen, S., Mosconi, R., \& Nielsen, B. (2000). Cointegration Analysis in the Presence of Structural Breaks in the Deterministic Trend. Econometrics Journal, 3(2), 216-249. https://doi.org/10.1111/1368-423X.00047

Juselius, K., \& Johansen, S. (1992). Testing Structural Hypotheses in a Multivariate Cointegration Analysis of the PPP and the UIP for UK. Journal of Econometrics, 53(1-3), 211-244. https://doi.org/10.1016/0304-4076(92)90086-7

Kraft, J., \& Kraft, A. (1978). On the Relationship between Energy and GNP. Journal of Energy and Development, 3(2), 401-403. https://www.jstor.org/stable/24806805

Kuznets, S. (1955). Economic Growth and Income Inequality. American Economic Review, 45(1), 1-28. https://www.jstor.org/stable/1811581

Lean, H. H., \& Smyth, R. (2010). Multivariate Granger Causality between Electricity Generation, Exports, Prices and GDP in Malaysia. Energy, 35(9), 3640-3648. https://doi.org/10.1016/j.energy.2010.05.008

Lotfalipour, M. R., Falahi, M. A., \& Ashena, M. (2010). Economic growth, $\mathrm{CO}_{2}$ emissions, and fossil fuels consumption in Iran. Energy, 35(12), 5115-5120. https://doi.org/10.1016/j.energy.2010.08.004

Menegaki, A. N. (2019). The ARDL Method in the Energy-Growth Nexus Field: Best Implementation Strategies. Economies, 7(4), 105. https://doi.org/10.3390/economies 7040105

Nazlioglu, S., Kayhan, S., \& Adiguzel, U. (2014). Electricity Consumption and Economic Growth in Turkey: Cointegration, Linear and Nonlinear Granger Causality. Energy Sources, Part B: Economics, Planning, and Policy, 9(4), 315-324. https://doi.org/10.1080/15567249.2010.495970

Odugbesan, J. A., \& Rjoub, H. (2021). Relationship among Economic Growth, Energy 
Consumption, $\mathrm{CO}_{2}$ Emission, and Urbanization: Evidence from MINT Countries. SAGA Open, 10(2), 1-15. https://doi.org/10.1177/2158244020914648

Ozturk, I. (2010). A Literature Survey on Energy-Growth Nexus. Energy Policy, 38(1), 340-349. https://doi.org/10.1016/j.enpol.2009.09.024

Pesaran, M. H., \& Pesaran, B. (2009). Time Series Econometrics Using Microfit 5.0. Oxford University Press.

Pesaran, M. H., Shin, Y., \& Smith, R. J. (2001). Bounds Testing Approaches to the Analysis of Level Relationships. Journal of Applied Econometrics, 16(3), 289-326. https://doi.org/10.1002/jae.616

Phillips, P. C. B., \& Perron, P. (1988). Testing for a Unit Root in Time Series Regression. Biometrika, 75(22), 335-346. https://doi.org/10.1093/biomet/75.2.335

Sajeev, A., \& Kaur, S. (2020). Environmental Sustainability, Trade and Economic Growth in India: Implications for Public Policy. International Trade, Politics and Development, 4(2), 141-160. https://doi.org/10.1108/ITPD-09-2020-0079

Shahbaz, M., Sharma, R., Sinha, A., \& Jiao, Z. (2021). Analyzing Nonlinear Impact of Economic Growth Drivers on $\mathrm{CO}_{2}$ Emissions: Designing an SDG Framework for India. Energy Policy, 148(Part B). https://doi.org/10.1016/j.enpol.2020.111965

Stern, D. I. (2004). The Rise and Fall of the Environmental Kuznets Curve. World Development, 32(8), 1419-1439. https://doi.org/10.1016/j.worlddev.2004.03.004

Sugiawan, Y., \& Managi, S. (2019). New Evidence of Energy-Growth Nexus from Inclusive Wealth. Renewable and Sustainable Energy Reviews, 103(April 2019), 40-48. https://doi.org/10.1016/j.rser.2018.12.044

Toda, H. Y., \& Phillips, P. C. B. (1993). Vector Autoregression and Causality. Econometrica, 61(6), 1367-1393. https://doi.org/10.2307/2951647

United Nations. (2019). The Sustainable Development Goals Report 2019. United Nations. https://unstats.un.org/sdgs/report/2019/The-Sustainable-Development-Goals-Report-2019.pdf

United Nations. (2021). Sustainable development. The 17 goals to Transform Our World. United Nations. https://sdgs.un.org/goals

\section{Notes}

Note 1. "Globally, crude oil prices fell from 100US\$ per barrel in mid-2014 to below 30US\$ per barrel in early 2016. Natural gas and coal prices also fell during this period. International Monetary Fund (IMF) quantifies lower fossil fuel prices to act as a form of economic stimulus" (Sajeev and Kaur, 2020).

Note 2. While the EKC hypothesis is applicable for other pollutants, the main concern is on $\mathrm{CO}_{2}$ due to its crucial impact on global warming and climate change. 
Note 3. The systematic, inverted-U relationship between income change and environmental quality derives its name from the work of Kuznets (1955) who postulated a similar relationship between income inequality and economic development.

Note 4. As there is no explicit reference to time, EKC is considered as a long run phenomenon.

Note 5. In empirically analysing the energy-growth nexus and EKC hypothesis, the omission-of-variable bias has been pointed out by several economists (see Ozturk, 2010; Lean and Smyth, 2010; Sajeev and Kaur, 2020).

Note 6. "The test of stationarity in time series econometrics literature is essential to ascertain the order of integration of a variable before proceeding to test for cointegration and causality test- to prevent spurious analysis and erroneous policy implications" (Etokakpan et al., 2020).

Note 7. While the Schwarz Bayesian criterion (SBC) is widely used, the R-bar squared criterion provided better estimates to the present study (see "5.2 ARDL results").

Note 8. Taking a level shift dummy into the cointegration test, we are more likely to find out a single cointegration $(r=1)$ and no autocorrelation (see Fukuda, 2020)

Note 9. As the present study aims at giving interference to Malaysia's EKC hypothesis, we do not provide the Model II results of the case whose dependent variable is EG (see "4.2 VECM procedure"). The results are provided on request.

\section{Copyrights}

Copyright for this article is retained by the author(s), with first publication rights granted to the journal.

This is an open-access article distributed under the terms and conditions of the Creative Commons Attribution license (http://creativecommons.org/licenses/by/4.0/) 